\title{
Data sharing policies of journals in life, health, and physical sciences indexed in Journal Citation Reports
}

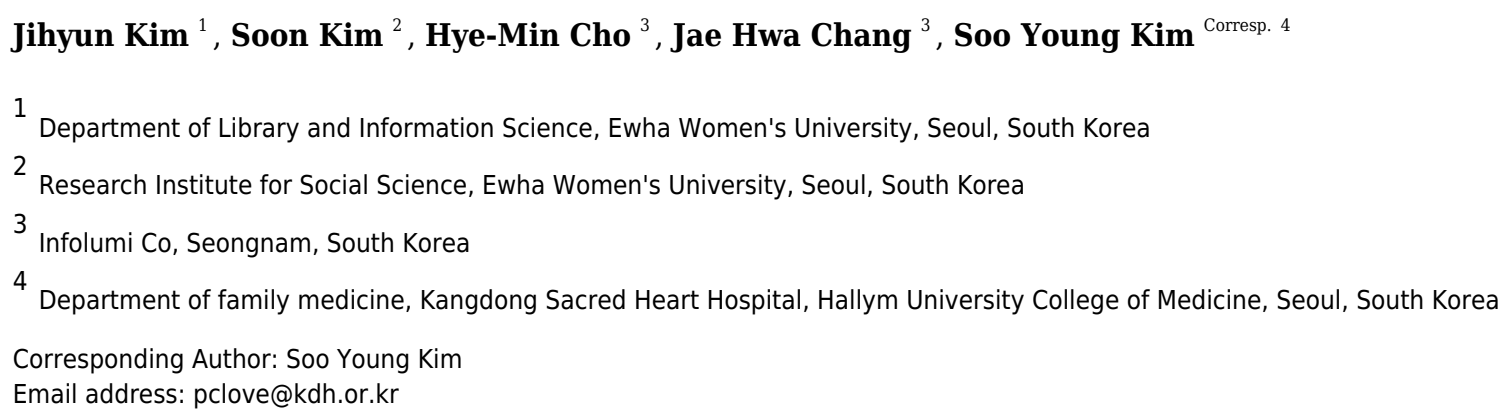

Background. Many scholarly journals have established their own data-related policies, which specify their enforcement of data sharing, the types of data to be submitted, and their procedures for making data available. However, except for the journal impact factor and the subject area, the factors associated with the overall strength of the data sharing policies of scholarly journals remain unknown. This study examines how factors, including impact factor, subject area, type of journal publisher, and geographical location of the publisher are related to the strength of the data sharing policy. Methods. From each of the 178 categories of the Web of Science's 2017 edition of Journal Citation Reports, the top journals in each quartile (Q1, Q2, Q3, and Q4) were selected in December 2018. Of the resulting 709 journals (5\%), 700 in the fields of life, health, and physical sciences were selected for analysis. Four of the authors independently reviewed the results of the journal website searches, categorized the journals' data sharing policies, and extracted the characteristics of individual journals. Univariate multinomial logistic regression analyses were initially conducted to determine whether there was a relationship between each factor and the strength of the data sharing policy. Based on the univariate analyses, a multivariate model was performed to further investigate the factors related to the presence and/or strength of the policy. Results. Of the 700 journals, 308 (44.0\%) had no data sharing policy, 125 (17.9\%) had a weak policy, and 267 (38.1\%) had a strong policy (expecting or mandating data sharing). The impact factor quartile was positively associated with the strength of the data sharing policies. Life science journals were more likely to have a strong policy relative to a weak policy than physical science journals (relative risk ratio [RRR], $0.36 ; 95 \%$ confidence interval [Cl], 0.17 to 0.78 ). Life science journals had a greater probability of having a weak policy relative to no policy than health science journals (RRR, 2.73; $95 \% \mathrm{Cl}, 1.05$ to 7.14 ). Contrary to some existing research, 
commercial publishers were more likely to have a data sharing policy than non-commercial publishers (RRR, 2.99; $95 \% \mathrm{Cl}, 1.85$ to 4.81 ). This finding may account for the increase in commercial publishers' engagement in data sharing. Journals by publishers in Europe, including the majority of those located in the United Kingdom and the Netherlands, were more likely to have a strong data sharing policy than a weak policy (RRR, 2.99;95\% Cl, 1.85 to 4.81 ). This result indicates that European national initiatives that encourage and mandate data sharing may influence the presence of a strong policy in the associated journals. Future research needs to explore the factors associated with varied degrees in the strength of a data sharing policy as well as more diverse characteristics of journals related to the policy strength. 


\section{Data sharing policies of journals in life, health, and physical}

\section{2 sciences indexed in Journal Citation Reports}

3

4 Jihyun Kim ${ }^{* 1}$, Soon Kim ${ }^{* 2}$, Hye-Min Cho $^{3}$, Jae Hwa Chang ${ }^{3}$, Soo Young Kim ${ }^{4}$

6 'Department of Library and Information Science, Ewha Womans University, Seoul, South Korea

$7 \quad{ }^{2}$ Research Institute for Social Science, Ewha Womans University, Seoul, South Korea

8 3Infolumi Co, Seongnam, South Korea

9 4department of family medicine medical college, Hallym University, Seoul, South Korea

11 *Both authors contributed equally to this manuscript 


\section{Abstract}

Background. Many scholarly journals have established their own data-related policies, which specify their enforcement of data sharing, the types of data to be submitted, and their procedures for making data available. However, except for the journal impact factor and the subject area, the factors associated with the overall strength of the data sharing policies of scholarly journals remain unknown. This study examines how factors, including impact factor, subject area, type of journal publisher, and geographical location of the publisher are related to the strength of the data sharing policy.

Methods. From each of the 178 categories of the Web of Science's 2017 edition of Journal Citation Reports, the top journals in each quartile (Q1, Q2, Q3, and Q4) were selected in December 2018. Of the resulting 709 journals (5\%), 700 in the fields of life, health, and physical sciences were selected for analysis. Four of the authors independently reviewed the results of the journal website searches, categorized the journals' data sharing policies, and extracted the characteristics of individual journals. Univariable multinomial logistic regression analyses were initially conducted to determine whether there was a relationship between each factor and the strength of the data sharing policy. Based on the univariable analyses, a multivariable model was performed to further investigate the factors related to the presence and/or strength of the policy.

Results. Of the 700 journals, 308 (44.0\%) had no data sharing policy, 125 (17.9\%) had a weak policy, and 267 (38.1\%) had a strong policy (expecting or mandating data sharing). The impact factor quartile was positively associated with the strength of the data sharing policies. Physical science journals were less likely to have a strong policy relative to a weak policy than Life science journals (relative risk ratio [RRR], 0.36 ; $95 \%$ confidence interval [CI], 0.17 to 0.78 ). 
38 Life science journals had a greater probability of having a weak policy relative to no policy than

39 health science journals (RRR, 2.73; 95\% CI, 1.05 to 7.14). Contrary to some existing research,

40 commercial publishers were more likely to have a weak policy relative to no policy than non-

41 commercial publishers (RRR, 7.87; 95\% CI, 3.98 to 15.57 ). This finding may account for the

42 increase in commercial publishers' engagement in data sharing. Journals by publishers in

43 Europe, including the majority of those located in the United Kingdom and the Netherlands,

44 were more likely to have a strong data sharing policy than a weak policy (RRR, 2.99; 95\% CI,

451.85 to 4.81$)$. This result indicates that European national initiatives that encourage and mandate

46 data sharing may influence the presence of a strong policy in the associated journals. Future

47 research needs to explore the factors associated with varied degrees in the strength of a data

48 sharing policy as well as more diverse characteristics of journals related to the policy strength. 
50

51

52

53

54

\section{INTRODUCTION}

The value of research data can be increased by making the data widely accessible to other researchers (i.e., data sharing) (Mozersky et al., 2019; Wang \& Lv, 2018). Data sharing may improve the rigor and reproducibility of research, thereby contributing to scientific advancements (Borgman, 2012). Many scholarly journals are increasingly establishing their own data policies, which specify the level of enforcement of data sharing, the types of data to be submitted, and the procedures for making data available (Gherghina \& Katsanidou, 2013). Several studies have examined the factors associated with journals' adoption of data sharing policies. The impact factor of a journal is the most cited element linked to the strength of its data sharing policies. The strength ranges from no policy, to weak policy (unenforceable), to strong (enforceable) policy (Piwowar \& Chapman, 2008). Some studies have indicated that journals with higher impact factors are more likely to require data sharing, as opposed to merely recommending it or not mentioning it at all (Piwowar \& Chapman, 2008; Sturges et al., 2015; Vasilevsky et al., 2017). Another group of studies also identified a positive relationship between impact factor and whether or not journals had data sharing policies (Aleixandre-Benavent et al., 2016; Crosas et al., 2019; Resnik et al., 2019; Stodden, Guo \& Ma, 2013; Vidal-Infer et al., 2018; Zenk-Moltgen \& Lepthien, 2014). In other research, however, no relationship was found between impact factor and the adoption of data sharing policies (Aleixandre-Benavent et al., 2019; Vidal-Infer et al., 2019).

Several possible explanations for this inconsistency exist. One possibility is that previous studies were limited to specific areas (e.g., dentistry, Vidal-Infer et al., 2018; pediatrics, ZenkMoltgen \& Lepthien, 2014; and toxicology, Aleixandre-Benavent, 2019). A second possibility is the variations in the definition of data sharing policies across studies. A third possibility is that 
73 there might be a temporal trend; data sharing policies were initially established by journals with

74 a higher impact factor and, over time, have been adopted by those with a lower impact factor.

In addition, disciplinary variations across journals influence the adoption of data sharing policies. One study analyzed the data sharing policies of 50 journals in the social sciences and demonstrated that the proportion of journals with data sharing policies varied across subject areas; for example, $74 \%$ of journals in economics had such policies, while only $18 \%$ of history journals did (Crosa et al., 2019). The results of another study suggested that biology journals were more likely to require data sharing than mathematics or social science journals (Resnik et al., 2019).

Additional factors besides impact factor and academic subject area were found to be significantly associated with the existence and strength of data sharing policies. The type of journal publisher was one such factor; as a previous study noted, non-commercial publishers, such as academic societies, were more likely to have a data sharing policy than commercial publishers (Piwowar \& Chapman, 2008). A later study, which focused solely on for-profit publishers, suggested that journals published by Elsevier, Wiley, and scientific societies had a significantly higher probability of having data- or code-sharing policies than those published by other for-profit publishers (Stodden, Guo \& Ma, 2013).

Geographical location is another factor that influences the strength of data sharing policies.

91 Clinical trial data sharing policies, for example, have evolved differently in Europe compared to 92 the United States, as the regulations governing data sharing practices vary by location. The 93 European Union's Transparency Law made the proactive sharing of non-summary clinical trial 94 data possible, but no similar act exists in the United States, where data sharing is reactive 95 (Westergren, 2016). 
96

In addition, data sharing requirements have been established primarily in the United States and several European countries, including the United Kingdom (UK) and the Netherlands. For example, the National Institutes of Health indicates they may expand upon existing data sharing requirements and require data management and sharing plans more broadly moving forward (National Institute of Health, 2019). UK Research and Innovation provides common principles on data policy, which emphasize making publicly funded research data openly available (UK Research and Innovation, 2018), while the Dutch government proposed the Netherland's Plan for Open Science to help make data easily accessible and reusable (European Commission, 2018). Furthermore, a larger European initiative called Plan S was proposed by Science Europe in 2018. Plan S requires all the results of publicly funded research in Europe to be published in open-access journals and/or deposited in open repositories with no embargoes. Plan S is another example that demonstrates that Europe has stronger open-access and open-data initiatives than other continents (European Science Foundation, 2018; Kim, 2019).

Minimal research has been conducted on the association between these journal aspects and the strength of data sharing policies across diverse fields of science. The current study thus examined whether the strength of the data sharing policies of journals in the fields of life, health, and physical sciences are affected by impact factor, subject area, type of publisher, and geographical location of the publisher. Exploring these factors will help elucidate which journal characteristics are related to the presence and/or strength of journal policies regarding data sharing.

\section{Data collection}


119 In December 2018, the highest-ranked journal in each journal impact factor quartile (Q1, $0<\mathrm{Z} \leq$

120

121

122

123

124

125

126

127

128

129

130

131

132

133

134

135

136

137

138

139

140

0.25; Q2, $0.25<\mathrm{Z} \leq 0.5$; Q3, $0.5<\mathrm{Z} \leq 0.75$; or $\mathrm{Q} 4,0.75<\mathrm{Z}$; Z, percentile rank) was selected

from each of the 178 categories of the 2017 edition of Journal Citation Reports (JCR). For example, Physics of Life Reviews, Biochimica et Biophysica Acta-Biomembranes, Biointerphases, and Radiation and Environmental Biophysics were selected for biophysics because they ranked first, respectively, among the Q1, Q2, Q3, and Q4 journals in biophysics. Because only one journal existed in the transportation category, we selected only this journal. From the remaining 177 categories, 708 journals were selected, comprising four journals (one in each of the four quartiles) in each of the 177 categories (i.e., 177 multiplied by 4). The selection process resulted in the original identification of 709 journals.

We then identified the journal subject areas based on four broad clusters, as defined by Scopus: life, health, physical, and social sciences (Elsevier, 2020). Although we selected the journals listed in JCR, the four subject areas were useful for creating a categorical variable that represented the subject areas. Because we focused on journals in life, health, and the physical sciences, we excluded five journals that were categorized solely under social sciences. In addition, we excluded four journals that were not listed in Scopus. As a result, the final set comprised 700 journals.

Each journal was assigned to one of the three subject areas-life, health, or physical sciences - or two or three of the subject areas simultaneously. According to Table 1, we identified 80 in life science, 154 in health science, and 305 in physical science. In terms of "multidiscipline" journals, we initially determined that 156 journals were assigned to more than one subject area. In addition, Scopus further divided the four subject areas into 26 subject 
141 categories plus one "general" category that contained multidisciplinary journals (García,

142 Rodriguez-Sánchez \& Fdez-Valdivia, 2011). We found five additional journals, including

143 Nature, categorized as "general" without assigning broad subject clusters. We considered the 156

144 journals as being assigned to more than one broad subject area and the five journals in the

145 general category as being multidisciplinary. Therefore, we included 161 journals in the

146 "multidiscipline" category. The subject area variable therefore consisted of four categories: life

147 science, health science, physical science, and multidiscipline. Moreover, of the 26 Scopus

148 subcategories, we used 22 subject categories - all except those related to the social sciences and

149 humanities - to perform further descriptive analyses of the relationship between subject areas

150 and the strength of data sharing policies.

151 In addition, we determined the strength of the data sharing policies provided by the 700

152 journals based on a modified version of Wiley's data sharing policy (Table 2) (Wiley, 2019).

153 This modification resulted from adding a "no policy" category to Wiley's policy and

154 categorizing the strength of the policy into three levels — no, weak, and strong — according to

155 Piwowar and Chapman (2008).

156 The four authors of this study were separated into two pairs, each of which was assigned

157 half of the journals. Each pair searched the assigned journals' web pages and information about

158 their data sharing policies, using keywords such as "data sharing," "data availability," and

159 “deposit." If there was no mention of data sharing on a journal's web page, the authors identified

160 it as having no data sharing policy. They determined that a journal had a weak data sharing

161 policy if it encouraged data sharing without any indication that it was mandated. As Table 2

162 illustrates, a strong data sharing policy included three degrees of strength: (1) expects data

163 sharing, which requires publishing a data availability statement only; (2) mandates data sharing, 
164 which requires both a data availability statement and data sharing; or (3) mandates the sharing 165 and peer review of data, which include all three requirements. The authors judged these criteria 166 based on the inclusion of words that indicated obligation, such as "must," "should," or "require." Within each group, two authors independently assigned relevant codes to the journals. The kappa statistic for measuring inter-rater reliability was 0.75 , which indicated substantial agreement (McHugh, 2012). After the initial coding, we compared the coding results and discussed the disparities to achieve agreement. The coding discrepancies were also discussed across the groups; accordingly, the four authors reached a consensus on the coding results. categorical variables. We presented type of publisher as a dichotomous variable - that is, commercial and non-commercial—as suggested by Piwowar and Chapman (2008). The commercial publishers consisted of major publishers, such as Elsevier, Springer Nature, and

Wiley, as well as a number of minor publishers. The non-commercial publishers were mostly academic societies or associations but also included several research institutes, university presses, and nonprofit foundations or organizations. publishers were located in the United States. The European publishers were located across 21 countries. The majority of the publishers comprised 178 from the UK and 60 from Netherlands. Other publishers were located in Asia, Australia, and Oceania. None in the "others" category represented the sample from the continents.

\section{Statistical analysis}

187 The data were analyzed using Stata ver. 16.1 (StataCorp., College Station, TX, USA). The 
188 strength of data sharing policies was a nominal variable with three categories: strong data

189 sharing policy (hereafter, "strong policy”), weak data sharing policy (hereafter, "weak policy”),

190 and no data sharing policy (hereafter, "no policy") (Table 2).

191 Both a univariable and a multivariable multinomial logistic regression analysis were

192 conducted, because the dependent variable — the strength of the data sharing policies — was

193 measured at the nominal level. Although the dependent variable had ordinal characteristics, we

194 used multinomial rather than ordinal logistic regression because a test of the proportional odds

195 assumption using ordinal regression demonstrated that the model failed to satisfy proportionality

$196\left(\chi^{2}(7)=14.68, p=0.04\right)$. Since multinomial regression does not assume proportional odds, this was

197 selected as the appropriate model.

198 Univariable multinomial logistic regression analyses were conducted to test the

199 association of each factor with the strength of data sharing policies. All significant factors with

$200 \mathrm{p}<0.05$ were included in the multivariable analysis. We assessed two-way interactions among

201 the factor categories, and there was no interaction effect except between publisher location and

202 subject area. To select best goodness of fit, we compared the Bayesian Information Criteria

203 (BIC) of the main effect model and with interaction variables included; the main effect model

204 had a lower BIC indicating better fit. To reduce the risk of overfitting, events per variable (EPV)

205 was also calculated based on the smallest number of observations in the outcome categories

206 divided by the number of effective regression coefficients (de Jong et al., 2019). Multivariable

207 multinomial logistic regression analyses were then performed to determine whether the

208 strength of data sharing policies can be predicted from the aforementioned factors.

Based on both of the analyses, we identified coefficients and standard errors and

210 calculated the associated relative risk ratios (RRRs) and 95\% confidence intervals (CIs). Wald 
211 tests for independent variables were also conducted to determine the significance of each

212 independent variable on all pair-wise comparisons for the dependent variable.

213

214 RESULTS

215 Journal characteristics

216 Out of 14,223 journals in the JCR in December 2018, 709 (5\%) were originally selected, and 700

217 in the life, health, and physical science categories were ultimately analyzed. Table 1 summarizes

218 the general characteristics of the journals. Among the 700 journals, $308(44.0 \%)$ had no data

219 sharing policy, $125(17.9 \%)$ had weak data sharing policies, and $267(38.1 \%)$ had strong data

220 sharing policies (at minimum expected data sharing).

221 Concerning the subject area variable, the journals that were categorized as

222 "multidiscipline" included 156 that were classified under two or three subject areas, and five 223 journals that fell under Scopus's "general” category. Specifically, there were 73 life and health

224 science journals, 61 life and physical science journals, 14 health and physical science journals, 8

225 in all three areas, and five journals in the general category. Thus, 307 journals - including 80 in

226 life sciences, 154 in health sciences, and 73 in both — were particularly relevant to the life and/or

227 health sciences, although almost all the journals in the "multidiscipline" category were somehow 228 related to either of these two subject areas.

229 The most common location for publishers was Europe (334, 47.7\%), followed by North

230 America (318 journals, 45.4\%), which mostly comprised the United States. The number of

231 commercial publishers $(531,75.9 \%)$ was more than three times that of non-commercial

232 publishers. The top three commercial publishers were Elsevier (147 journals), Springer Nature

233 (118 journals), and Wiley (72 journals). 
235 Univariable analysis of factors associated with the strength of data sharing policies

236 To examine the associations between the strength of data sharing policies and each factor, we

237 carried out univariable multinomial logistic regression analyses. "Weak policy" was set as a base 238 outcome category. Among the correlates that were tested individually to determine their

239

240

241 relationships to policy strength, all factors showed significant associations $(\mathrm{p}<0.05)$. Comparing no policy to weak policy, type of publisher was significant. Impact factor quartile, publisher location, and subject area were also significant when comparing strong to weak policy (Table 3). Wald tests for independent variables in the univariable analysis were also performed to determine the significance of an independent variable across all pair-wise comparisons of the category levels (no, weak, and strong policy). Table 3 showed that overall, all independent variables were significant at the $\mathrm{p}<0.001$ level. Therefore, we rejected the null hypothesis that the coefficients of the dummy variables indicating each independent variable were jointly equal to zero.

Based on the univariable analysis, all the factors were eligible for inclusion in the multivariable model. All possible two-way interactions for the variables selected for the multivariable model were also tested but were not statistically significant at the $p=0.05$ level, with the exception of the interaction variable between publisher location (Europe) and subject area (health science and physical science). We compared the model fit between the main-effect model that included the four factors only and the model with the interaction variable. As seen in Table 4, the addition of the interaction variable did not improve the model fit. The Bayesian information criteria (BIC) was smaller in the main-effect model, and the difference in BICs was 39.07; this is much greater than 10, which is strong evidence for choosing the main-effect model (Raftery, 1995). Therefore, our final model for the multivariable analysis consisted of the four 
258 factors without interaction terms. EPV was 6.94 (125 divided by 18), which exceeded the

259 minimum EPV values of between 5 and 20 for reliable results (Ogundimu, Altman \& Collins, 260 2016).

261

262

Multivariable analysis of the factors associated with the strength of data sharing policies

263

Multivariable multinomial logistic regression analyses were performed to determine whether

264 the four journal characteristics — impact factor, type of publisher, location of publisher, and subject area - predict the strength of data sharing policies. The reference group of the outcome variable was "weak policy." Overall, the multinomial logistic regression model was significant $\left(\chi^{2}(18)=234.17, \mathrm{p}<0.001\right)$.

According to Table 5, the multinomial log-odds for having no policy relative to a weak policy was related to type of publisher and subject area. Specifically, journals from noncommercial publishers (RRR, 7.87; 95\% CI, 3.98 to 15.57) had a significantly higher likelihood of having no data sharing policy than those from commercial publishers. In addition, health science journals (RRR, 2.73; 95\% CI, 1.05 to 7.14 ) had a significantly higher probability of having no data sharing policy than life science journals. significantly associated with impact factor, location of publisher, and subject area. In particular, journals in impact factors Q3 (RRR, 0.51; 95\% CI, 0.27 to 0.96) and Q4 (RRR, 0.24; 95\% CI, 0.12 to 0.49 ) had a significantly lower likelihood of adopting a strong data sharing policy than those in Q1. Journals with publishers in Europe had a higher likelihood of adopting a strong policy (RRR, 2.99; 95\% CI, 1.85 to 4.81) than those with publishers in North America. 
281 probability of having a strong data sharing policy than life science journals.

282

283

284

285

286

287

288

289

290

291

292

293

294

295

296

297

298

299

300

301

302

303

304

In particular, we plotted the predicted probabilities of the impact factor quartiles for the strength of the data sharing policies to examine the patterns of policy strength by the journals' impact factor quartiles. Figure 1 shows that the probability of a journal having no data sharing policy increases as its impact factor decreases. In contrast, the probability of a journal having a strong data sharing policy increases as its impact factor increases. No linear trend for journals with weak policies was identified with regard to their impact factor quartile rankings.

We also performed Wald tests for independent variables, which suggested that overall, all factors were significant at the $\mathrm{p}<0.001$ level (Table 5). We could reject the null hypothesis that the coefficients for the dummy variables indicating each factor were simultaneously equal to zero. The results suggested that all the factors should be included in the multivariable model.

\section{Distribution of policy strength across Scopus subject categories}

The multinomial logistic regression analyses indicated that compared to the life science journals, the health science journals were more likely to have no policy relative to a weak policy and that the physical science journals had a lower likelihood of having a strong policy relative to a weak policy. The results implied that the life science journals had a greater probability of having strong data sharing policies than the physical science journals did. The life science journals were also more likely to have at least weak data sharing policies than the health science journals.

The findings were consistent with the analysis of subject areas based on the proportion of journals having strong data sharing policies across 22 Scopus subcategories of subject. According to Table 6, neuroscience (68\%) had the highest proportion of journals with a strong policy, followed by immunology and microbiology (65\%); environmental science (53\%); biochemistry, genetics, and molecular biology (51\%); and chemical engineering (46\%). With the 
305

306

307

308

309

310

311

312

313

314

315

316

317

318

319

320

321

322

323

exception of journals in chemical engineering, subject categories with a high proportion of journals with strong data sharing policies were closely related to the life sciences.

The category with the lowest proportion of journals with a strong policy was mathematics (11\%), followed by computer science (28\%), health professions $(29 \%)$, and nursing and veterinary journals (33\%) (Table 6). Mathematics and computer science were considered fields in the physical sciences, and the remaining subjects were categorized as health sciences. Journals in these fields tended not to have strong data sharing policies.

\section{DISCUSSION}

The results of the multinomial logistic regression analyses presented in Table 3 and Table 5 demonstrate generally consistent findings in both the univariable (unadjusted) and multivariable (adjusted) models. In comparing journals with no data sharing policy relative to a weak policy, type of publishers was significant in both models and the effect was higher in the multivariable model (unadjusted RRR, 7.08; adjusted RRR, 7.87). Subject area was not significant in the univariable analysis, but it was found to have a significant association with the strength of the data sharing policy in the multivariable model (adjusted RRR, 2.73). In comparing journals with a strong data sharing policy relative to a weak policy, impact factor quartile, journal publisher's location, and subject area were significant in both models. In particular, the effect size of the publishers' location was greater in the multivariable model (unadjusted RRR, 2.17; adjusted RRR, 2.99).

To summarize the overall results, approximately one-third of the 700 JCR journals had a strong data sharing policy (at a minimum, they expected data sharing). The factors relating to whether journals had no data sharing policy or a weak policy included type of publisher and 
328 subject area, when controlling for other variables. Journal impact factor, geographical location of

329 the publisher, and subject area were significantly associated with whether journals had a strong 330 policy or a weak policy, when other variables were held constant.

331 In this study, within the strong policy category, $38.1 \%$ of the journals at least expected

332 data sharing, while $13.8 \%$ mandated data sharing. While it is difficult to make accurate

333 comparisons because of the use of different standards, the percentage of journals that mandated

334 data sharing seems to be somewhat higher than reported in previous studies. Vasilevsky et al.

335 (2017) reported that $11.9 \%$ of the journals in the 2013 JCR required data sharing for

336 publications, and a survey of the editors of scientific journals in Korea found that only $3.4 \%$ of

337 journals mandated data sharing (Kim, Yi \& Huh, 2019). When a data sharing policy was defined

338 as including statements regarding complementary material, significant differences in the

339 percentages of the journals requiring were found among different domains: $83.5 \%$ for pediatric

340 journals (Aleixandre-Benavent et al., 2019); 50\% for information science and library science

341 journals (Sturges et al., 2015); 47\% for dental journals (Vidal-Infer et al., 2018); and 4.7\% for

342 scientific journals on substance abuse (Resnik et al., 2019).

343 Journal impact factor did not appear to have a significant effect on whether journals had

344 no policy or a weak policy, although several studies suggested that impact factor was positively

345 related to having data sharing policies (Aleixandre-Benavent et al., 2016; Crosas et al., 2019;

346 Resnik et al., 2019; Stodden, Guo \& Ma, 2013; Vidal-Infer et al., 2018; Zenk-Moltgen \&

347 Lepthien, 2014). However, we did identify a significant association between impact factor and

348 having a strong data sharing policy relative to a weak policy. Similar results were reported by

349 previous studies (Piwowar \& Chapman, 2008; Sturges et al., 2015; Vasilevsky et al., 2017).

350 Particularly, we found that journals in Q1 were more likely to have a strong data sharing policy 
351 than a weak policy, in comparison to journals in Q3 and Q4. Overall, the findings were partially

352 consistent with the results reported in existing research.

353 Our findings demonstrated that the subject areas of the journals predicted the strength of

354 the data sharing policies: life science journals were more likely to have a strong policy relative to

355 a weak policy than physical science journals, and they tended to have a weak policy relative to

356 no policy in comparison to health science journals. The descriptive analysis also showed that the

357 rate of adoption of a strong data sharing policy was higher for journals in the field of life

358 sciences, such as neuroscience (68\%) and immunology and microbiology (65\%), than journals in

359 the fields of physical sciences, such as mathematics (11\%) and computer science (28\%). The

360 results were consistent with those reported by Resnik et al. (2019), suggesting that journals in the

361 field of biology tend to mandate data sharing more than those in the fields of mathematics or

362 social sciences. Similarly, Hrynaszkiewicz et al. (2017) reported that life science journals tended

363 to have weak or strong data sharing policies. Data sharing practices also differed by discipline

364 due to variations in the researchers' attitudes toward data management and data sharing, as well

365 as the infrastructure and expertise of data curation (Key Perspectives, 2010). Existing data

366 sharing norms and practices in the field of life sciences would contribute to establishing these

367 data sharing policies (Pham-Kanter, Zinner \& Campbell 2014).

368 Moreover, the type of publisher affected whether journals have no data sharing policy

369 relative to a weak policy. That is, journals by commercial publishers were more likely to have a

370 weak policy rather than no policy in comparison to non-commercial publishers. This finding is in

371 opposition to that of Piwowar and Chapman (2008), who found that non-commercial publishers

372 were more likely to have data sharing policies because they supported data sharing more

373 promptly than commercial publishers. Their study was published in 2008, and we considered the 
374 inconsistency as being reflective of changes in the commercial publishers' attitudes toward data

375 sharing since that time, particularly those of major commercial publishers. According to Stodden,

376 Guo \& Ma (2013), major publishers, such as Elsevier and Wiley, are more likely to have data

377 sharing policies than other for-profit publishers.

The geographical location of publishers was a significant factor associated with the

380

381

382

383

384

385

386

387

388

389

390

391

392

393

395

396 strength of the journals' data sharing policies. Specifically, journals from publishers in Europe were more likely to have a strong policy relative to a weak policy than journals from publishers in North America. However, there was no significant association between the location of the publishers and whether the journals have no policy versus a weak policy. These findings imply that journals from publishers in Europe are likely to have strong data sharing policies since the presence of national initiatives, such as Plan S in Europe, might influence the strength of the data sharing policies of the journals in those locations.

Scholarly journals are one of the major formal scientific communication channels that pressure authors to engage in data sharing, and those data sharing requirements have been found to have an impact on data sharing norms and behaviors (Kim \& Burns, 2016). In this sense, journals play a significant role in fostering the culture of open science by establishing and implementing a data sharing policy. This study contributes to better understanding the interplay between journals' characteristics and the strength of data sharing policies. It also addresses the implications of the policy trend that encourages data sharing or at least expects it.

\section{CONCLUSIONS}

95 The present study identified the significant factors that influence the strength of a journal's data sharing policy, specifically the probability of having no data sharing policy as well as that of 
397 having a strong data sharing policy compared to a weak policy. Subject area was a commonly

398 identified factor, indicating that life science journals were more likely to have either a strong or a

399 weak policy in comparison to physical science journals and health science journals, respectively.

400 Journal impact factor positively affected the likelihood of having a strong policy relative to a

401 weak policy.

402 It is interesting to note that non-commercial publishers were more likely to have no data 403 sharing policy in comparison to commercial publishers, which tended to have at least a weak 404 policy. The result is in contrast to the findings reported in a previous study, which implies a 405 change in the commercial publishers' reactions to data sharing. It is also worth mentioning that 406 the publishers' location might affect the strength of their data sharing policies. Europe has 407 several national initiatives that enhance and require open data. Thus, it is possible that journals 408 by publishers in Europe are influenced by these actions and have stronger data sharing policies. 409 The type of publisher and journal publisher location are factors that have been less frequently 410 recognized than impact factor and subject area. This study contributes to the existing literature 411 by empirically identifying additional factors that are associated with the strength of a data 412 sharing policy This study has some limitations that should be addressed in future research. First, for this analysis, the strength of the data sharing policies was categorized as no, weak, and strong according to Piwowar and Chapman (2008), while other studies adopted more nuanced approaches (Stodden et al., 2013; Vasilevsky et al., 2017; Resnik et al., 2019). Specifically, a data sharing policy that 417 only required a data availability statement might not be a "strong" policy since previous studies demonstrated that such statements did not necessarily mean data were actually shared (Federer et al., 2018; McDonald et al., 2017; Naudet et al., 2018; Rowhani-Farid \& Barnett, 2016). 
420 Therefore, future research should incorporate varying degrees of strength in relation to data sharing

421 policies that represent subtle differences in a policy's enforceability. Second, other factors can

422 affect the presence or the strength of a data sharing policy, for example the age of the journals or

423 the language used in the journals (Gherghina \& Katsanidou, 2013; Crosas et al., 2019). The effects

424 of more diverse journal characteristics on the strength of a data sharing policy therefore need to be

425 examined in future research.

426

427 Data availability statement

428 The data that support the findings of this study are openly available in figshare at

429 https://figshare.com/s/ef7756774f8d3d4fff2a.

430 


\section{REFERENCES}

432 Aleixandre-Benavent R, Moreno-Solano LM, Sapena AF, Perez EA. 2016. Correlation between

433 impact factor and public availability of published research data in Information Science and

434 Library Science journals. Scientometrics 107:1-13.

435 Aleixandre-Benavent R, Sapena AF, Ferrer SC, Peset F, Garcia AG. 2019. Policies regarding

436 public availability of published research data in pediatrics journals. Scientometrics 118:439-

437 451 DOI: $10.1007 / \mathrm{s} 11192-018-2978-1$.

438

Borgman CL. 2012. The conundrum of sharing research data. Journal of the American Society for Information Science and Technology 63:1059-1078 DOI: 10.1002/asi.22634

Crosas M, Gautier J, Karcher S, Kirilova D, Otalora G, Schwartz A. 2019. Data policies of highly-ranked social science journals. Center for Open Science. Available at https://osf.io/wpfuz (accessed 10 April 2019)

de Jong VM, Eijkemans MJ, van Calster B, Timmerman D, Moons KG, Steyerberg EW, van Smeden M. 2019. Sample size considerations and predictive performance of multinomial logistic prediction models. Statistics in Medicine 38:1601-1619 DOI: $\underline{10.1002 / \mathrm{sim} .8063}$

Elsevier. 2020. Scopus content coverage guide. Available at https://www.elsevier.com/_data/assets/pdf_file/0007/69451/Scopus_ContentCoverage_Guid

European Science Foundation. 2018. Why Plan S. Available at https://www.coalition-s.org/whyplan-s/ (accessed 4 April 2020)

European Commission. 2018. The Netherlands' Plan on Open Science: Open Science Monitor Case Study. Available at https://op.europa.eu/en/publication-detail/-/publication/20d4026e4478-11e9-a8ed-01aa75ed71a1 (accessed 6 April 2020) 
454 García JA, Rodriguez-Sánchez R, Fdez-Valdivia J. 2011. Ranking of the subject areas of 455 Scopus. Journal of the American Society for Information Science and Technology 62:20132023 DOI: $\underline{10.1002 / \text { asi.21589 }}$

457 Gherghina S, Katsanidou A. 2013. Data availability in political science journals. European Political Science 12:333-349 DOI: 10.1057/eps.2013.8.

459

460

461

462

463

464

465

466

467

468

469

470

471

472

473

474

475

476

Federer L, Belter CW, Joubert D, Livinski A, Lu YL, Snyders LN, Thompson H. 2018. Data sharing in PLOS ONE: an analysis of Data Availability Statements. PLoS One 13:e0194768 DOI: $\underline{10.1371 / \text { journal.pone.0194768 }}$

Hrynaszkiewicz I, Birukou A, Astell M, Swaminathan S, Kenall A, Khodiyar V. 2017. Standardising and harmonising research data policy in scholarly publishing. International Journal of Digital Curation 12:65-71 DOI: 10.2218/ijdc.v12i1.531

Key Perspectives. 2010. Data dimensions: disciplinary differences in research data sharing, reuse and long term viability: DCC SCARP synthesis report. Digital Curation Centre. Available at http://www.dcc.ac.uk/sites/default/files/SCARP\%20SYNTHESIS_FINAL.pdf_(accessed 10 April 2019)

Kim K. 2019. Plan S. Korean Council of Science Editors Newsletter 31:8-9.

Kim SY, Yi HJ, Huh S. 2019. Current and planned adoption of data sharing policies by editors of Korean scholarly journals. Science Editing 6:19-24 DOI: 10.6087/kcse.151.

Kim Y, Burns CS. 2016. Norms of data sharing in biological sciences: The roles of metadata, data repository, and journal and funding requirements. Journal of Information Science, 42: 230-245 DOI: $\underline{10.1177 / 0165551515592098}$

McDonald L, Schultze A, Simpson A, Graham S, Wasiak R, Ramagopalan SV. 2017. A review of data sharing statements in observational studies published in the BMJ: a cross-sectional 
study. F1000Research 6:1708 DOI: 10.12688/f1000research.12673.1

478

479

480

481

482

483

484

485

486

487

488

489

490

491

492

493

494

495

496

497

498

499

McHugh ML. 2012. Interrater reliability: the kappa statistic. Biochemia Medica 22:276-282

DOI: 10.11613/BM.2012.031

Mozersky J, Walsh H, Parsons M, McIntosh T, Baldwin K, DuBois JM. 2019. Are we ready to share qualitative research data? Knowledge and preparedness among qualitative researchers, IRB Members, and data repository curators. IASSIST Quarterly 43:1-23 DOI: $\underline{10.29173 / \text { iq } 952 .}$

National Institute of Health. 2019. DRAFT NIH policy for data management and sharing. Available at https://osp.od.nih.gov/wpcontent/uploads/Draft_NIH_Policy_Data_Management_and_Sharing.pdf (accessed 6 April 2020)

Naudet F, Sakarovitch C, Janiaud P, Cristea I, Fanelli D, Moher D, Ioannidis JPA. 2018. Data sharing and reanalysis of randomized controlled trials in leading biomedical journals with a full data sharing policy: survey of studies published in The BMJ and PLOS Medicine. BMJ 360:k400 DOI: 10.1136/BMJ.K400

Ogundimu EO, Altman DG, Collins GS. 2016. Adequate sample size for developing prediction models is not simply related to events per variable. Journal of Clinical Epidemiology 76:175182 DOI: $\underline{10.1016 / j . j c l i n e p i .2016 .02 .031}$

Pham-Kanter G, Zinner DE, Campbell EG. 2014. Codifying collegiality: recent developments in data sharing policy in the life sciences. PLoS One 9:e108451 DOI:

\section{$\underline{10.1371 / \text { journal.pone.0108451 }}$}

Piwowar HA, Chapman WW. 2008. A review of journal policies for sharing research data. In: Sustainability in the age of web 2.0: Proceedings of the 12th International Conference on 
500

501

502

503

504

505

506

507

508

509

510

511

512

513

514

515

516

517

518

519

520

521

522

Electronic Publishing; 2008; Toronto, Canada. Toronto: ELPUB. Available at https://elpub.architexturez.net/system/files/pdf/001 elpub2008.content.pdf (accessed 10 April 2019)

Raftery AE. 1995. Bayesian model selection in social research. Sociological Methodology 25:111-163.

Resnik DB, Morales M, Landrum R, Shi M, Minnier J, Vasilevsky N, Champieux RE. 2019. Effect of impact factor and discipline on journal data sharing policies. Accountability in Research 26:139-156 DOI: 10.1080/08989621.2019.1591277.

Rowhani-Farid A, Barnett AG. 2016. Has open data arrived at the British Medical Journal (BMJ)? An observational study. BMJ Open 6:1-8 DOI: 10.1136/bmjopen-2016-011784

Stodden V, Guo P, Ma Z. 2013. Toward reproducible computational research: an empirical analysis of data and code policy adoption by journals. PLoS One 8:e67111 DOI: 10.1371/journal.pone.0067111.

Sturges P, Bamkin M, Anders JH, Hubbard B, Hussain A, Heeley M. 2015. Research data sharing: Developing a stakeholder-driven model for journal policies. Journal of the Association for Information Science and Technology 66:2445-2455 DOI: 10.1002/asi.23336.

UK Research and Innovation. 2015. Guidance on best practice in the management of research data. Available at https://www.ukri.org/files/legacy/documents/rcukcommonprinciplesondatapolicy-pdf/ (accessed 6 April 2020)

Vasilevsky NA, Minnier J, Haendel MA, Champieux RE. 2017. Reproducible and reusable research: Are journal data sharing policies meeting the mark? PeerJ 5:e3208.

Vidal-Infer A, Aleixandre-Benavent R, Lucas-Dominguez R, Sixto-Costoya A. 2019. The

Peer) reviewing PDF | (2020:01:44641:2:0:NEW 21 Jul 2020) 
523 availability of raw data in substance abuse scientific journals. Journal of Substance Use

$524 \quad 24: 36-40$ DOI: 10.1080/14659891.2018.1489905.

525 Vidal-Infer A, Tarazona B, Alonso-Arroyo A, Aleixandre-Benavent R. 2018. Public availability

526 of research data in dentistry journals indexed in Journal Citation Reports. Clinical Oral

527 Investigations 22:275-280 DOI: 10.1007/s00784-017-2108-0.

528 Wang S, Lv X. 2018. The analysis and design of data sharing platform for universities based on

529 blockchain technology. In 2018 3rd International Conference on Automation, Mechanical

530 Control and Computational Engineering (AMCCE 2018). Atlantis Press. DOI:

$531 \quad \underline{10.2991 / \text { amcce-18.2018.28 }}$

532 Westergren A. 2016. The data liberation movement: regulation of clinical sharing in the

533 European Union and the United States. Houston Journal of International Law 38:887-913.

534 Wiley. 2019. Wiley's data sharing policies. John Wiley \& Sons. Available at

535 https://authorservices.wiley.com/author-resources/Journal-Authors/open-access/data-sharing-

$536 \quad$ citation/data-sharing-policy.html (accessed 3 April 2019)

537 Zenk-Moltgen W, Lepthien G. 2014. Data sharing in sociology journals. Online Information

$538 \quad$ Review 38:709-722. 


\section{Table $\mathbf{1}$ (on next page)}

Strength of data sharing policies.

Modified from Wiley's policy for data sharing (

https://authorservices.wiley.com/author-resources/Journal-Authors/open-access/data-sharingcitation/data-sharing-policy.html ). 
1 Table 1:

2 Strength of data sharing policies.

\begin{tabular}{|c|l|l|l|l|l|}
\hline Code & $\begin{array}{c}\text { Strength of } \\
\text { policy }\end{array}$ & \multicolumn{1}{|c|}{$\begin{array}{c}\text { Data sharing policy } \\
\text { categories }\end{array}$} & $\begin{array}{r}\text { Data availability } \\
\text { statement is } \\
\text { published }\end{array}$ & $\begin{array}{c}\text { Data have } \\
\text { been } \\
\text { shared }\end{array}$ & $\begin{array}{c}\text { Data have } \\
\text { been peer- } \\
\text { reviewed }\end{array}$ \\
\hline 0 & No policy & No data sharing policy & No mention of data sharing & \\
\hline 1 & Weak policy & Encourages data sharing & Optional & Optional & Optional \\
\hline 2 & \multirow{2}{*}{ Strong policy } & Expects data sharing & Required & Optional & Optional \\
\cline { 4 - 6 } & & Mandates data sharing & Required & Required & Optional \\
\cline { 4 - 6 } & & Mandates data sharing & Required & Required & Required \\
\hline 4 & & and peer reviews data & & & \\
\hline
\end{tabular}

3 Modified from Wiley's policy for data sharing (https://authorservices.wiley.com/author-resources/Journal-

4 Authors/open-access/data-sharing-citation/data-sharing-policy.html). 


\section{Table 2 (on next page)}

General characteristics of the journals $(n=700)$.

${ }^{a}$ Q1, first quartile; Q2, second quartile; Q3, third quartile; Q4, fourth quartile. 
1 Table 2:

2 General characteristics of the journals $(n=700)$.

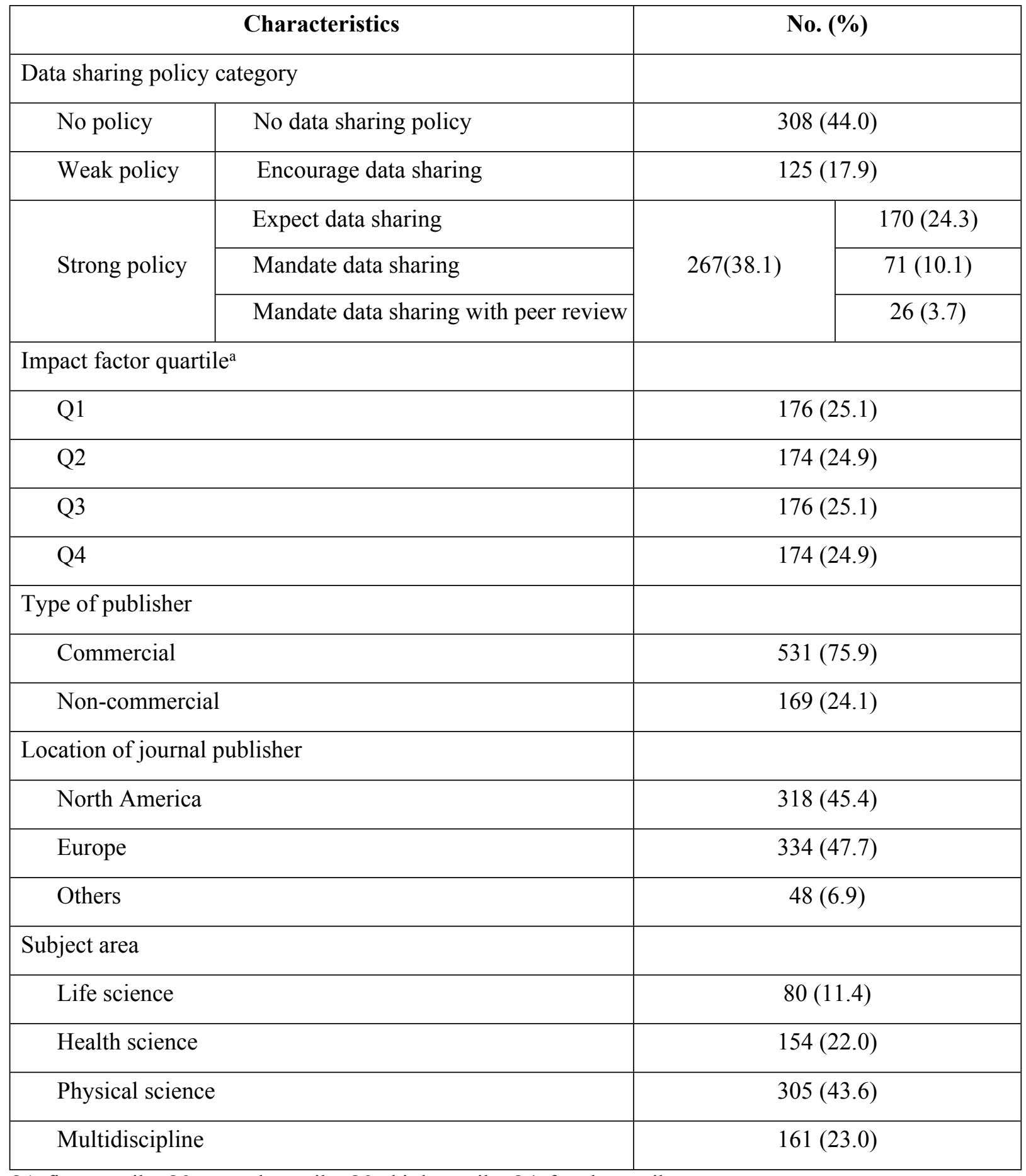

$3{ }^{\mathrm{a}} \mathrm{Q}$ 1, first quartile; Q2, second quartile; Q3, third quartile; Q4, fourth quartile.

4 


\section{Table 3 (on next page)}

Results of univariable multinomial logistic regression analysis and wald tests for independent variables

${ }^{a} \mathrm{RRR}$, relative risk ratio; ${ }^{\mathrm{b}} \mathrm{Q} 1$, first quartile; $\mathrm{Q} 2$, second quartile; $\mathrm{Q}$, third quartile; $\mathrm{Q} 4$, fourth quartile. 
1 Table 3:

2 Results of univariable multinomial logistic regression analysis and wald tests for independent

3 variables

4 a : RRR, relative risk ratio; b: Q1, first quartile; Q2, second quartile; Q3, third quartile; Q4, fourth quartile.

\begin{tabular}{|c|c|c|c|c|c|c|c|}
\hline Statistics & \multicolumn{3}{|c|}{ No policy vs. Weak policy } & \multicolumn{3}{|c|}{ Strong policy vs. Weak policy } & \multirow{2}{*}{$\begin{array}{c}\begin{array}{c}\text { Wald } \\
\text { tests }\end{array} \\
\text { p-value }\end{array}$} \\
\hline Factors & $\mathrm{RRR}^{\mathrm{a}}$ & $95 \% \mathrm{CI}$ & p-value & RRR & $95 \% \mathrm{CI}$ & $\mathrm{p}$-value & \\
\hline \multicolumn{7}{|l|}{ Impact factor quartile ${ }^{b}$} & $<0.001$ \\
\hline Q1 & 1(Ref) & - & - & 1(Ref) & - & - & - \\
\hline Q2 & 0.63 & $0.34-1.19$ & 0.15 & 0.72 & $0.40-1.30$ & 0.28 & 0.36 \\
\hline Q3 & 0.82 & $0.44-1.50$ & 0.51 & 0.52 & $0.29-0.95$ & 0.03 & 0.05 \\
\hline Q4 & 1.55 & $0.84-2.86$ & 0.16 & 0.26 & 0.13-0.51 & $<0.001$ & $<0.001$ \\
\hline \multicolumn{8}{|l|}{ Type of publisher } \\
\hline Commercial & 1(Ref) & - & - & 1(Ref) & - & - & - \\
\hline Non-commercial & 7.08 & 3.66-13.69 & $<0.001$ & 1.46 & $0.71-3.00$ & 0.30 & $<0.001$ \\
\hline \multicolumn{7}{|c|}{ Location of journal publisher } & $<0.001$ \\
\hline North America & 1(Ref) & - & - & 1(Ref) & - & - & \\
\hline Europe & 0.79 & $0.51-1.21$ & 0.28 & 2.17 & $1.40-3.38$ & $<0.001$ & $<0.001$ \\
\hline Others & 2.15 & $0.86-5.37$ & 0.10 & 1.07 & $0.36-3.15$ & 0.09 & 0.09 \\
\hline \multicolumn{7}{|l|}{ Subject area } & $<0.001$ \\
\hline Life science & 1(Ref) & - & - & 1(Ref) & - & - & - \\
\hline Health science & 2.54 & $1.01-6.40$ & 0.05 & 1.59 & $0.62-4.06$ & 0.33 & 0.08 \\
\hline Physical science & 0.50 & $0.24-1.03$ & 0.06 & 0.38 & 0.18-0.80 & 0.01 & 0.04 \\
\hline Multi-discipline & 0.80 & $0.35-1.85$ & 0.60 & 1.22 & $0.53-2.79$ & 0.63 & 0.36 \\
\hline
\end{tabular}




\title{
Table 4(on next page)
}

Comparison of the model fit

\author{
${ }^{a}$ Bayesian Information Criteria
}


1 Table 4:

2 Comparison of the model fit

\begin{tabular}{|l|l|c|c|}
\hline \multicolumn{2}{|l|}{} & Main-effect model & $\begin{array}{c}\text { Model with the } \\
\text { Model } \\
\text { Fit statistics }\end{array}$ \\
\hline $\begin{array}{l}\text { Log } \\
\text { likelihood } \\
\text { Ratio tests }\end{array}$ & Chi-square & 234.17 & 273.71 \\
\cline { 2 - 4 } & p-value & 18 & 30 \\
\hline BIC $^{\text {a }}$ & $<0.001$ & $<0.001$ \\
\hline
\end{tabular}

3

${ }^{a}$ Bayesian Information Criteria 


\section{Table 5 (on next page)}

Results of multivariable multinomial logistic regression analysis and wald tests for independent variables

${ }^{a} \mathrm{RRR}$, relative risk ratio; ${ }^{\mathrm{b}} \mathrm{Q} 1$, first quartile; $\mathrm{Q} 2$, second quartile; $\mathrm{Q}$, third quartile; $\mathrm{Q} 4$, fourth quartile. 
2

4

5

6$$
7
$$

8

9

10

11

12

13

14

15

16

17

18

19

20

21

22

22

Table 5:

Results of multivariable multinomial logistic regression analysis and wald tests for independent variables

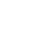

7

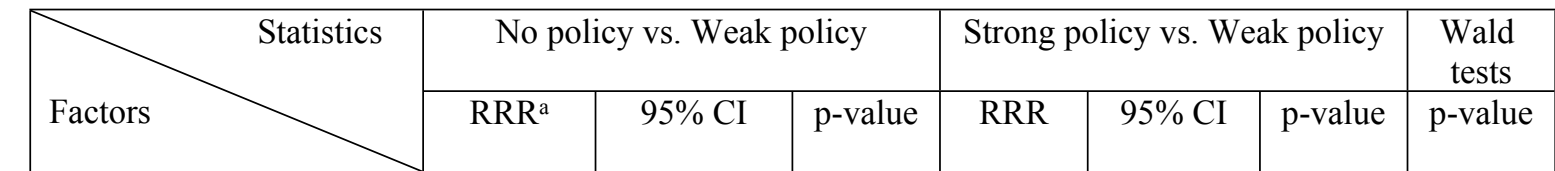
\begin{tabular}{|l|l|}
\hline Impact factor quartile & $<\mathbf{0 . 0 0 1}$ \\
\hline Q &
\end{tabular}

\begin{tabular}{|l|c|c|c|c|c|c|c|}
\hline Q1 & 1 (Ref) & - & - & 1 (Ref) & - & - & - \\
\hline Q2 & 0.70 & $0.36-1.38$ & 0.31 & 0.70 & $0.37-1.30$ & 0.26 & 0.50 \\
\hline
\end{tabular}

\begin{tabular}{|l|l|l|l|l|l|l|l|}
\hline Q3 & 0.70 & $0.36-1.38$ & 0.31 & 0.70 & $0.37-1.30$ & 0.26 & 0.50 \\
\hline
\end{tabular}

\begin{tabular}{|l|l|l|l|l|l|l|l|} 
Q4 & 1.70 & $0.87-3.29$ & 0.12 & $\mathbf{0 . 2 4}$ & $\mathbf{0 . 1 2 - 0 . 4 9}$ & $<\mathbf{0 . 0 0 1}$ & $<0.001$ \\
\hline
\end{tabular}

Type of publisher

\begin{tabular}{|l|c|c|c|c|c|c|c|} 
Commercial & 1 (Ref) & - & - & 1 (Ref) & - & - & - \\
\hline Non-commercial & $\mathbf{7 . 8 7}$ & $\mathbf{3 . 9 8 - 1 5 . 5 7}$ & $<\mathbf{0 . 0 0 1}$ & 1.87 & $0.89-3.94$ & 0.10 & $<\mathbf{0 . 0 0 1}$ \\
\hline
\end{tabular}

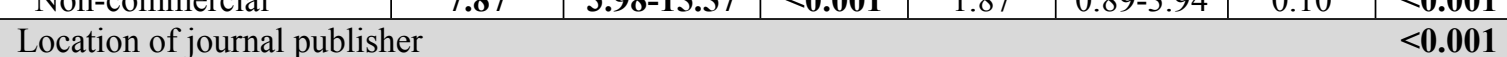

\begin{tabular}{|l|c|c|c|c|c|c|c|}
\hline North America & 1 (Ref) & - & - & 1 (Ref) & - & - & - \\
\hline
\end{tabular}

\begin{tabular}{|l|c|c|c|c|c|c|c|}
\hline Europe & 1.13 & $0.70-1.81$ & 0.62 & $\mathbf{2 . 9 9}$ & $\mathbf{1 . 8 5 - 4 . 8 1}$ & $<0.001$ & $<0.001$ \\
\hline Others & 1.39 & $0.51-3.79$ & 0.52 & 1.33 & $0.42-4.15$ & 0.81 & 0.81 \\
\hline
\end{tabular}

\begin{tabular}{|l|l|r|r}
\hline Subject area & $<\mathbf{0 . 0 0 1}$ \\
\hline
\end{tabular}

\begin{tabular}{|l|c|c|c|c|c|c|c|}
\hline Life science & 1 Ref) & - & - & 1 (Ref) & - & - & - \\
\hline Health science & $\mathbf{2 . 7 3}$ & $\mathbf{1 . 0 5 - 7 . 1 4}$ & $\mathbf{0 . 0 4}$ & 1.98 & $0.75-5.19$ & 0.17 & 0.12 \\
\hline Physical science & 0.46 & $0.21-1.01$ & 0.05 & $\mathbf{0 . 3 6}$ & $\mathbf{0 . 1 7 - 0 . 7 8}$ & $\mathbf{0 . 0 1}$ & 0.03 \\
\hline Multi-discipline & 0.80 & $0.33-1.92$ & 0.61 & 1.37 & $0.58-3.23$ & 0.47 & 0.27 \\
\hline
\end{tabular}


Table 6(on next page)

The rankings of top and bottom five categories according to the number of journals with strong policies 
1 Table 6:

2 The rankings of top and bottom five categories according to the number of journals with strong 3 policies

\begin{tabular}{|c|l|l|}
\hline Ranking & \multicolumn{1}{|c|}{ Top 5 } & \multicolumn{1}{|c|}{ Bottom 5 } \\
\hline 1 & Neuroscience (68\%) & Mathematics (11\%) \\
\hline 2 & Immunology and microbiology (65\%) & Computer science (28\%) \\
\hline 3 & Environmental science (53\%) & Health professions (29\%) \\
\hline 4 & Biochemistry, genetics, and molecular biology (51\%) & Nursing (33\%) \\
\hline 5 & Chemical engineering (46\%) & Veterinary (33\%) \\
\hline
\end{tabular}

4 
Figure 1

Adjusted predictions of impact factor quartiles for the strength of data sharing policies.

(A) Adjusted prediction of impact factor quartiles for "no policy" category, (B) adjusted prediction of impact factor quartiles for "weak policy" category, and (C) adjusted prediction of impact factor quartiles for "strong policy" category. IF, impact factor; $\mathrm{Cl}$, confidence interval.
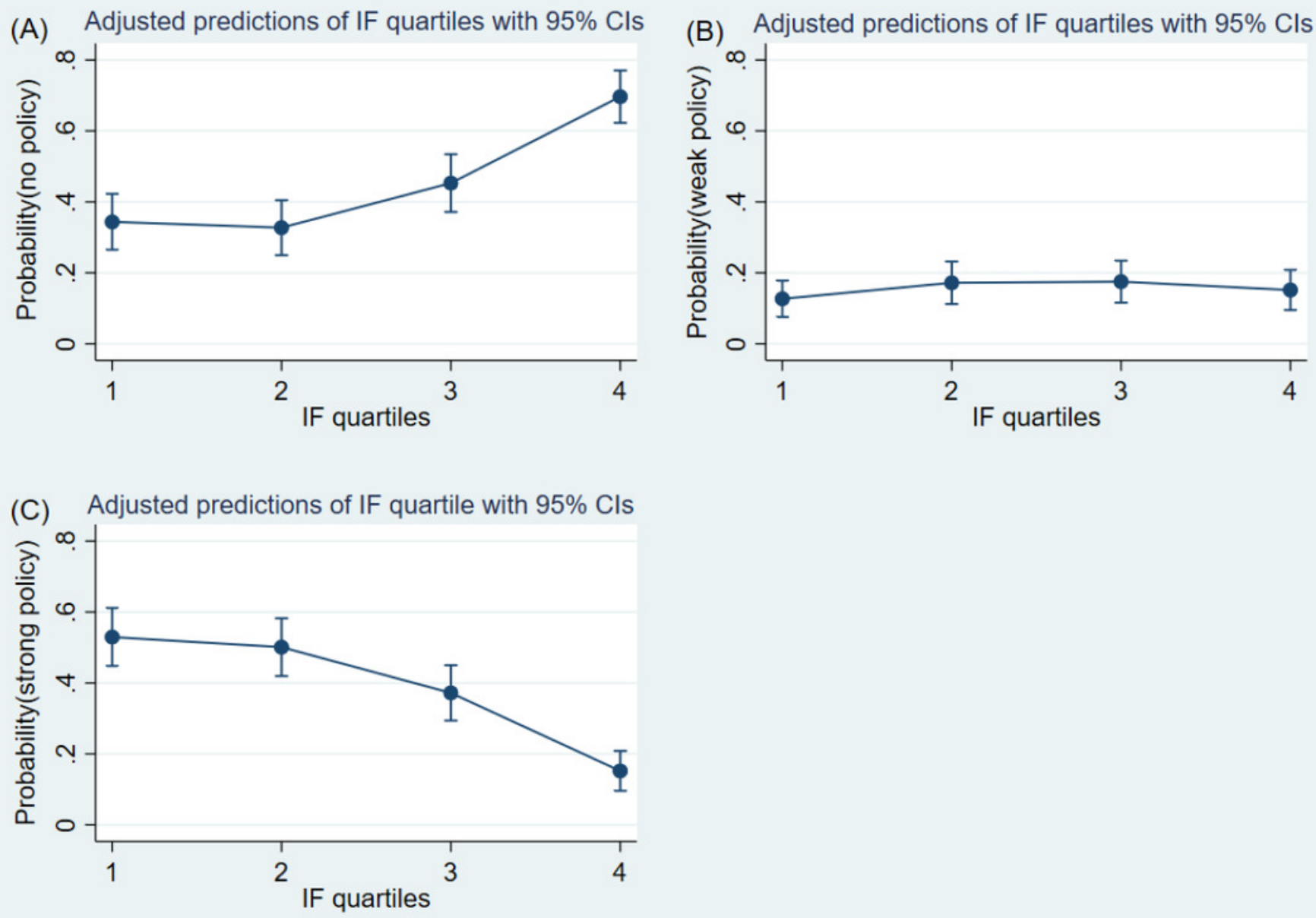